\title{
PERANAN ELEKTROKARDIOGRAFI PADA HIPERTROFI VENTRIKEL KIRI
}

\author{
Nikko Nugraha ${ }^{1}$, Hauda El Rasyid ${ }^{2}$ \\ Fakultas Kedokteran, Universitas Andalas-RSUP Dr M Djamil Padang, Jl Perintis Kemerdekaan No. 94 \\ email: nikkonugraha@gmail.com
}

Submitted: 10-04-2020,Reviewer: 11-04-2020,Accepted: 20-04-2020

\begin{abstract}
Abstrak
Hipertensi merupakan massalah kesehatan global dan faktor risiko utama morbiditas dan mortalitas penyakit kardiovaskular (PKV). Pemeriksaan baku emas untuk mendiagnosis HVK adalah dengan menggunakan ekokardiografi dan magnetic resonance imaging (MRI). Tidak semua fasilitas kesehatan mampu melakukan pemeriksaan ini dan mahal. Elektrokardiografi (EKG) merupakan pemeriksaan yang dimiliki hampir di semua fasilitas kesehatan. Pemeriksaan ini murah dan mudah untuk digunakan. tahun 2009, American Heart Association/American College Cardiology Fondation/Heart Rhythm Study (AHA/ACCF/HRS) mengeluarkan daftar 36 kriteria EKG untuk diagnosis HVK namun sensitivitasnya relative rendah. Tinjauan pustaka ini bertujuan untuk menjelaskan peranan EKG untuk memprediksi hipertrofi ventrikel kiri khususnya pada hipertensi.
\end{abstract}

Kata kunci: Hipertrofi ventrikel, kriteria elektrokardiografi, hipertensi

\begin{abstract}
Hypertension is a global health problem and a major risk factor for cardiovascular disease (PKV) morbidity and mortality. The gold standard examination for diagnosing HVK is to use echocardiography and magnetic resonance imaging (MRI). Not all health facilities can afford this examination and are expensive. Electrocardiography (ECG) is an examination that is held in almost all health facilities. This check is cheap and easy to use. In 2009, the American Heart Association / American College Cardiology Foundation / Heart Rhythm Study (AHA / ACCF / HRS) issued a list of 36 ECG criteria for the diagnosis of HVK but their sensitivity was relatively low. This literature review aims to explain the role of ECGs to predict left ventricular hypertrophy especially in hypertension.
\end{abstract}

Keywords: Ventricular hypertrophy, electrocardiographic criteria, hypertension 


\section{PENDAhuluan}

\subsection{Latar Belakang}

Hipertensi merupakan massalah kesehatan global dan faktor risiko utama morbiditas dan mortalitas penyakit kardiovaskular (PKV). Insiden hipertensi $31,1 \%$ pada populasi dewasa dan dari pasien hipertensi 36-41\% akan menderita penyakit jantung hipertensi (PJH) dan mengembangkan hipertrofi ventrikel kiri $(\mathrm{HVK}){ }^{1}$

Pemeriksaan baku emas untuk mendiagnosis HVK adalah dengan menggunakan ekokardiografi dan magnetic resonance imaging (MRI). Sayangnya tidak semua fasilitas kesehatan mampu melakukan pemeriksaan ini dan mahal. ${ }^{2}$ Pemeriksaan ekokardiografi juga bergantung pada operator, meskipun pemeriksaan ini dapat menilai HVK secara akurat.

Sebagai alternatif, elektrokardiografi (EKG) merupakan pemeriksaan yang dimiliki hampir di semua fasilitas kesehatan. Pemeriksaan ini murah dan mudah untuk digunakan serta tidak bergantung operator. Beberapa kriteria EKG yang digunakan untuk mendeteksi adanya HVK mempunyai sensitivitas rendah (30-50\%) meskipun spesifisitasnya tinggi $(90 \%){ }^{3}$

Pada tahun 2009, American Heart Association/American College Cardiology Fondation/Heart Rhythm Study (AHA/ACCF/HRS) mengeluarkan daftar 36 kriteria EKG untuk diagnosis HVK. Kriteria ini didasari pada pengukuran tegangan QRS, perhitungan durasi QRS, penggunaan gabungan dari beberapa kriteria, dan indeks berdasarkan skor yang diperoleh dari menggabungkan beberapa faktor elektrokardiografi. ${ }^{4}$ Kriteria untuk menilai HVK diantaranya yang sering digunakan adalah indeks Sokolow-Lyon, Voltase Cornell, serta sistem skor Romhilts Estes. ${ }^{5}$

Pada tahun 2017, Peguero-Lo Presti (PLP) mengajukan sebuah kriteria HVK sebagai $\mathrm{S}$ terdalam (S Deepest(SD)) ditambah $\mathrm{S}$ di $\mathrm{V} 4 \geq 2.8 \mathrm{mv}$ (pria) $\geq 2.3 \mathrm{mv}$ (wanita) mempunyai nilai sensitivitas $57 \%$ dan nilai spesifisitas $90 \%$ dalam menegakkan diagnosis HVK. $^{6}$ Dengan menggunakan beberapa kriteria EKG kiri diharapkan dapat mendiagnosis HVK terutama pada pasien hipertensi. Tinjauan pustaka ini bertujuan untuk menjelaskan peranan EKG untuk memprediksi hipertrofi ventrikel kiri khususnya pada hipertensi.

\section{TINJAUAN PUSTAKA}

\subsection{Hipertensi}

Hipertensi menurut JNC VII didefinisikan sebagai peningkatan tekanan darah sistolik $\geq 140 \mathrm{mmHg}$, tekanan darah diastolik $\geq 90 \mathrm{mmHg}$ atau sedang mengkonsumsi obat anti hipertensi. Hipertensi dapat menyebabkan PJH. Penyakit jantung hipertensi didefinisikan sebagai perubahan struktur, fungsi miokard, dan sistem konduksi jantung sebagai akibat dari tekanan darah tinggi yang berkepanjangan, yang berkontribusi terhadap peningkatan morbiditas dan kematian. $^{7}$

Terjadinya hipertrofi ventrikel kiri adalah sebagai konsekuensi hipertensi. Biasanya berupa peningkatan ketebalan dinding, dengan atau tanpa peningkatan ukuran rongga jantung. Peningkatan massa otot sebagian besar merupakan akibat dari peningkatan kronis afterload dari ventrikel kiri (VK) yang disebabkan hipertensi, meskipun ada juga pengaruh genetik. Peningkatan signifikan jumlah dan / atau ukuran sarkomer setiap sel miokard merupakan mekanisme patologis terjadinya HVK. $^{8}$

\subsection{Peranan Elektrokardiografi pada hipertrofi ventrikel kiri}

Elektrokardiografi merupakan tes paling penting untuk interpretasi irama jantung, kelainan sistem konduksi, deteksi 
iskemia miokard, dan deteksi kelainan ruang jantung termasuk hipertrofi ventrikel kiri. ${ }^{9}$

Terjadinya HVK sebagai konsekuensi hipertensi biasanya berupa peningkatan ketebalan dinding, dengan atau tanpa peningkatan ukuran rongga jantung. Peningkatan massa otot sebagian besar merupakan akibat dari peningkatan kronis afterload VK yang disebabkan hipertensi, meskipun ada juga pengaruh genetik. Peningkatan signifikan jumlah dan / atau ukuran sarkomer setiap sel miokard merupakan mekanisme patologis terjadinya HVK $^{8}$ Hipertensi dapat menyebabkan perubahan massa dan ukuran VK. Hal ini ditandai peningkatan abnormal massa VK akibat peningkatan ketebalan dinding, peningkatan ukuran rongga, atau keduanya. Pola elektrokardiografi dari HVK terjadi akibat:

A.Penebalan dari massa otot

Ada korelasi yang jelas antara peningkatan ketebalan massa ventrikel dengan tinggi dari gelombang $\mathrm{R}$. Gelombang R yaitu defleksi positif yang pertama kali muncul, baik disertai atau tidak oleh gelombang Q. Banyak kriteria EKG HVK menggunakan peningkatan gelombang $\mathrm{R}$ di sadapan prekordial kiri seperti pada kriteria cornell. Alasan kenapa terjadi peningkatan voltase belum terlalu jelas penyebabnya. ${ }^{10}$

B. Perlambatan Konduksi

Ketika miokardium menebal abnormal, aktivitas elektrik membutuhkan waktu untuk menyeberang ke seluruh jantung sehingga durasi kompleks QRS menjadi lebar (memperpanjang waktu depolarisasi) yang disebut sebagai HVK dengan pelebaran QRS. Repolarisasi mungkin berefek dengan mekanisme yang sama menyebabkan segmen ST dan T abnormal yang disebut juga HVK dengan repolarisasi abnormal. ${ }^{10}$

Peningkatan massa otot mengakibatkan perlambatan dan perubahan dari konduksi, sehingga meningkatkan lebar dari kompleks QRS. Biasanya bisa melebihi 0.12 detik. Hal ini juga mengakibatkan peningkatan waktu aktivasi ventrikel (ventrikel activation time (VAT)) atau defleksi intrinsik. ${ }^{11}$

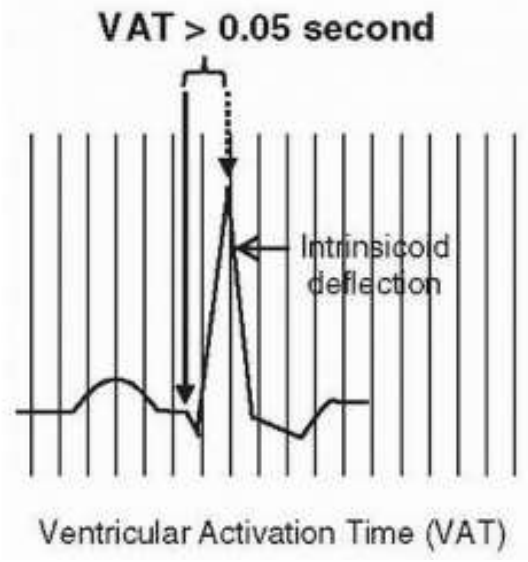

Gambar 2.1 Pemanjangan defleksi intrisicoid

C. Perubahan endokard

ST segmen depresi mungkin dapat dilihat pada sadapan yang merefleksikan potensial epikardial. Hal ini mungkin akibat perubahan endokard, dimana awalnya terjadi iskemia kemudian menjadi fibrosis. Fibrosis sering terjadi pada hipertrofi ventrikel kiri dan salah satu penanda adanya HVK. ${ }^{10}$

D. Perubahan repolarisasi

Perubahan akibat repolarisasi menyebabkan gelombang inversi $\mathrm{T}$. Inversi ini mempunyai karakteristik setelah ST interval definit dan asimetris. Inversinya mungkin bisa dangkal atau dalam. ${ }^{10}$

Pola tipikal yang mana merefleksikan permukaan epicardial dari ventrikel yang hipertrofi menyebabkan ;

1. Gelombang $\mathrm{R}$ yang tinggi

2. Pemanjangan dari interval QRS,

3. Pemanjangan dari waktu aktivasi ventrikel,

4. Segmen ST depresi dan gelombang $\mathrm{T}$ inversi. Abnormalitas dari gelombang ST dan $\mathrm{T}$ ini kemudian disebut sebagai strain. 


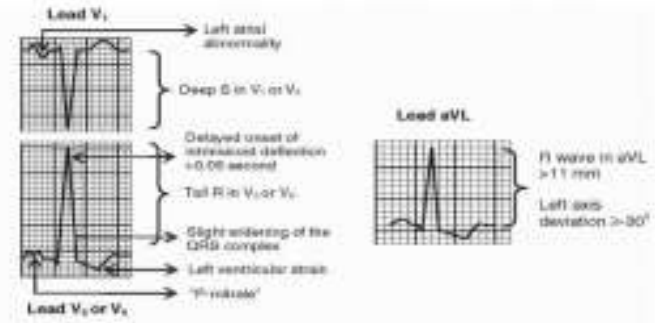

Gambar 2.2 Gambaran perubahan EKG HVK $^{9}$

Pola EKG dapat berubah selama evolusi penyakit. Pola strain muncul lebih berhubungan dengan durasi penyakit daripada adanya perbedaan tipe kelebihan beban hemodinamik. Gelombang Q di V5V6 lebih sering pada regurgitasi aorta lama daripada stenosis aorta. Tidak adanya gelombang Q di V6 mungkin berhubungan dengan fibrosis septal interstitial, substrat dari blok berkas cabang kiri parsial daripada hemodinamik overload. Pola pembesaran VK biasanya menetap namun bisa saja terjadi resolusi dengan pengobatan antihipertensi. $^{12}$

Pada sadapan ekstremitas, kompleks epikardial dari VK terekam di aVL, gelombang $\mathrm{R}$ dengan ST depresi dan $\mathrm{T}$ inversi bisa muncul pada sadapan ini dan temuan gelombang $\mathrm{R}$ lebih dari $13 \mathrm{~mm}$ konsisten dengan HVK. Pada sadapan ekstremitas gelombang $\mathrm{R}$ tinggi abnormal dengan ST depresi dan $\mathrm{T}$ inversi akan terlihat pada sadapan V4-V6. Interval QRS akan meningkat lebih dari 0.1 detik dan waktu aktivasi intrinsik lebih 0,05 detik, Gelombang S di sadapan precordial kanan merupakan refleksi dari potensial VK lebih besar dan gelombang ini akan menjadi lebih dalam abnormal. ${ }^{13}$

Berikut ini adalah kelainan EKG diamati pada pasien dengan HVK:

1. Abnormalitas gelombang $\mathrm{P}$ akibat peningkatan ukuran atrium kiri.

2. Ada peningkatan amplitudo tegangan QRS.

3. Ada peningkatan durasi QRS. Pada tahap lanjut blok cabang bundel kiri dapat terlihat.
4. Deviasi aksis kiri pada pasien hipertensi menunjukkan adanya HVK.

5. Kelainan repolarisasi (Perubahan gelombang ST-T).

Selain hal tersebut, progresi gelombang $\mathrm{R}$ lambat (V1-V3), meskipun tidak spesifik, dapat dilihat pada pasien dengan HVK.

\subsubsection{Abnormalitas gelombang $P$}

Abnormalitas gelombang $\mathrm{P}$ diketahui berhubungan dengan dilatasi atrium kiri, hipertrofi, penundaan konduksi, atau meningkatnya tekanan. Hal tersebut sering dikaitkan dengan HVK. Perubahan gelombang-P sering terjadi pada pasien hipertensi, dan mungkin menjadi tanda awal EKG dari PJH. Namun, kelainan gelombang $\mathrm{P}$ dapat juga terjadi tanpa adanya HVK. Belum adanya studi klinis yang memadai untuk menilai akurasi kriteria ini, baik sendiri atau dalam kombinasi dengan kriteria lain, kelainan gelombang $\mathrm{P}$ hanya dapat digunakan sebagai kriteria tambahan. Adanya gelombang $\mathrm{P}$ lebar ( $\mathrm{P}$ mitral) di sadapan inferior atau gelombang $\mathrm{P}$ dominan negatif dalam sadapan V1 meningkatkan kecurigaan HVK. ${ }^{14}$

\subsubsection{Peningkatan amplitudo QRS}

Diperlukan waktu lebih lama untuk impuls listrik melintasi otot ventrikel yang mengalami hipertrofi. Amplitudo impuls dapat meningkat karena adanya massa otot yang lebih besar. Dengan demikian, kompleks QRS memiliki amplitudo yang meningkat dan seringkali sedikit melebar. Hal ini mencerminkan pemanjangan konduksi intraventrikular. ${ }^{10}$

Peningkatan massa VK dapat menambah amplitudo tegangan yang dihasilkan oleh otot miokard. Efek ini dapat meningkatkan amplitudo gelombang positif (gelombang R) yang direkam di atas dada kiri dan kekuatan gelombang negatif (gelombang S) yang direkam di atas dada kanan. Hipertrofi ventrikel juga meningkatkan amplitudo gelombang $\mathrm{R}$ pada sadapan ekstremitas yang merekam proyeksi 
gaya positif (biasanya I dan aVL dengan sumbu QRS horizontal atau kiri). ${ }^{15}$

\subsubsection{Peningkatan durasi $Q R S$}

Peningkatan massa ventrikel kiri sering dikaitkan dengan pelebaran durasi QRS. Pelebaran ini terutama diakibatkan perlambatan pada fase awal kompleks QRS menjadi > 0,04 detik (waktu untuk mencapai puncak gelombang $\mathrm{R}$ tertunda); Hal ini dikenal sebagai keterlambatan defleksi intrinsicoid. Pola dari voltase QRS tinggi mungkin terlihat pada orang muda yang memiliki dinding dada tipis. ${ }^{9}$

Peningkatan durasi QRS dapat dikaitkan dengan peningkatan ketebalan dinding VK dan fibrosis intramural, yang mendistorsi dan memperpanjang propagasi impuls transmural. Peningkatan durasi QRS biasanya kecil atau mungkin terkait adanya blok cabang berkas kiri (left bundle branch block (LBBB) tidak lengkap yang umumnya juga sering menyertai HVK. Selain itu, beberapa penyebab HVK dapat menyebabkan perubahan ini dengan mekanisme lain seperti kalsifikasi atau fibrosis sistem konduksi ventrikel proksimal yang terletak dekat dengan cincin katup pada kalsifikasi stenosis aorta. ${ }^{11}$

Hipertrofi ventrikel kiri sering dikaitkan dengan interval QT yang sedikit memanjang, tetapi tidak diketahui apakah perpanjangan interval QT memiliki nilai independen sebagai kriteria elektrokardiografi untuk HVK atau hanya sekunder alibat perpanjangan durasi QRS. Pemanjangan interval QT sering ditemukan pada HVK tetapi tidak secara spesifik dapat digunakan dalam diagnosis HVK. Perpanjangan interval QT dapat mencerminkan potensi aksi transmembran yang lebih lama karena perubahan saluran ion sebagai bagian dari proses hipertrofik. ${ }^{12}$

\subsubsection{Deviasi sumbu kiri}

Secara umum, peningkatan ventrikel kiri menyebabkan peningkatan amplitudo dan durasi QRS, serta perubahan vektor mengarah lebih ke posterior. Hal ini menjelaskan kenapa QRS lebih dominan negatif pada sadapan prekordial. Kadang perubahan vektor QRS mungkin berhubungan dengan levorotasi dari jantung atau hipertrofi yang lebih signifikan pada area septal dibandingkan free wall seperti pada kasus kardiomiopati hipertrofi. ${ }^{15}$

Hipertrofi VK sering dikaitkan dengan blok fasikulus anterior kiri atau blok berkas cabang kiri yang tidak lengkap, yang dapat menggeser sumbu QRS lebih jelas ke kiri. ${ }^{10}$

\subsubsection{Kelainan repolarisasi}

Hipertrofi ventrikel kiri karena beban tekanan kronis berat (missal; hipertensi sistolik lama atau stenosis aorta berat), sering dikaitkan dengan depresi ST dan inversi gelombang $\mathrm{T}$ pada sadapan dengan gelombang $\mathrm{R}$ yang relatif tinggi. Pola ini sering disebut sebagai "VK strain". Hal ini mungkin terjadi akibat perubahan dalam repolarisasi otot jantung yang mengalami hipertrofi atau iskemia subendokardial relatif (permintaan suplai oksigen ke otot yang hipertrofi lebih besar dari pasokan) atau bisa juga akibat kelainan repolarisasi otot jantung hipertrofi. Perubahan paling sering terlihat pada sadapan lateral kiri (I, aVL, V5-6), namun dapat terjadi pada sadapan inferior

\subsection{Perkembangan kriteria EKG HVK}

Beberapa kriteria diagnostik telah digunakan untuk diagnosis HVK. Sensitivitas EKG untuk mendeteksi HVK bervariasi tergantung pada derajat peningkatan tekanan darah dan prevalensi HVK dalam populasi, tetapi telah terbukti selalu sensitivas lebih rendah dari 50\% dikaitkan dengan spesifisitas yang baik, mulai dari 85-100\%. Pada tahun 2009, berdasarkan AHA/ACCF/HRS pada hipertrofi ruang jantung mendokumentasikan 36 kriteria yang dapat digunakan untuk deteksi hipertrofi ventrikel kiri. ${ }^{4}$ Kriteria ini disusun berdasarkan : 
- Voltase sadapan ekstremitas

- Voltase sadapan precordial

- Kombinasi kriteria precordial dan ekstremitas

- Kombinasi kriteria votase dan non voltase

- Kombinasi kriteria dengan blok fasikuler anterior dan blok berkas cabang

Mayoritas kriteria menggunakan kriteria voltase (Cornell dan SokolowLyon) yang merefleksikan perubahan spasial dari arus listrik pada HVK. Salah satu kriteria menggunakan kriteria kombinasi parameter adalah sistem skor Romhilts Estes (SRE) yaitu aksis deviasi kiri, perubahan defleksi intrinsic, Perubahan segmen ST-T dan gelombang $\mathrm{P}^{4,16}$

Beberapa kriteria EKG saat ini juga mempunyai keterbatasan, yang sebagian karena fakta kegunaannya berbeda menurut kelompok populasi. Menurut teori Bayes, kemungkinan bahwa EKG mungkin berguna untuk mendiagnosis pembesaran ventrikel kiri cukup tinggi pada kelompok hipertensi berat dan rendah pada orang dewasa normotensif tanpa gejala. ${ }^{17}$

Ada banyak kriteria berbasis voltase untuk identifikasi HVK. Kriteria berbasis voltase yang banyak digunakan termasuk SokolowLyon dan voltase Cornell, Ukuran voltase didapat dengan menjumlahkan amplitudo $\mathrm{R}$ dan $\mathrm{S}$ pada suatu sadapan digunakan pada kriteria Sokolow - Lyon dan Cornell. Kriteria menurut voltase memiliki kekurangan karena beberapa faktor seperti massa tubuh dan lemak subkutan dapat mempengaruhi voltase sehingga menyebabkan penurunan sensitivitas. ${ }^{16}$
Tabel 2.1 Kriteria EKG HVK ${ }^{17}$

\begin{tabular}{|c|c|c|}
\hline vortage crituvia & Sensitivey $N$ & Specincity /86, \\
\hline$|\mathrm{Al}+5 \| 1|>25 \mathrm{~mm}$ & 10.6 & 100 \\
\hline $2 \mathrm{FVL}>11 \mathrm{~mm}$ & 11 & 100 \\
\hline $3 \mathrm{FML}>7.5 \mathrm{~min}$ & 22 & 96 \\
\hline $45 \mathrm{~V} 1+$ FVS-VE $\geq 35 \mathrm{~mm}$ \{Sockolow - Lyon\} & 22 & 100 \\
\hline 5 FNs-VE $>26 \mathrm{~mm}$ & 25 & 90 \\
\hline $6 \mathrm{HVL}$ - 5V3> $>28$ mm (men) or $20 \mathrm{~mm}$ (wornen) & 42 & 86 \\
\hline \multicolumn{3}{|l|}{ (Comel volage criterion) } \\
\hline 7 Coenel votage dunution measuarement & 51 & 96 \\
\hline \multicolumn{3}{|l|}{ Ofis auration $>$ Comet volugen $>2436$ mming } \\
\hline in in VI-VE, the deepest $S+$ the taleet $A>45 \mathrm{~mm}$ & 45 & $\infty$ \\
\hline - Aorthit-Estes score >4 points & 50 & as \\
\hline 10 Pomhit-Ertes score $>5$ points & 35 & 86 \\
\hline
\end{tabular}

Penelitian oleh Peguero dkk (2017) pada 97 orang dilakukan untuk mencari metode yang lebih baik untuk mendiagnosis HVK dari EKG. Kriteria didapatkan dari penjumlahan dari amplitudo gelombang S yang paling dalam (deepest $S$ wave, SD) pada satu sadapan manapun dan gelombang S di sadapan V4 (SV4). Pada kasus dimana $S$ yang paling dalam berada pada sadapan V4, maka nilai amplitudo SV4 dikali dua. Pasien dinyatakan dengan HVK bila SD + $\mathrm{S} 4 \geq 2,8 \mathrm{mV}$ untuk pria dan $\geq 2,3 \mathrm{mV}$ untuk wanita. $^{6}$

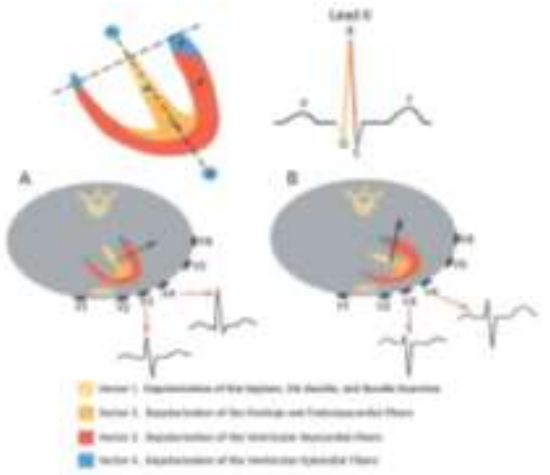

\section{Gambar 2.4 Kriteria EKG untuk diagnosis HVK7}

Dari gambar 2.5. Pada keadaan jantung normal (A) terjadi depolarisasi ventrikel kanan dan kiri, namun dominan di VK. vektor depolarisasi jantung terbagi 4 vektor utama. Umumnya pada $30 \mathrm{~ms}$ awal gelombang QRS terjadi depolarisasi pada septum, His, cabang berkas dan serabut purkinye. Setelahnya depolarisasi miokardi, epikard, dan free wall yang diwakili oleh gelombang akhir QRS (Gelombang S). Serabut miokard dalam keadaan normal (panah hitam), yakni predominan horizontal, 
sehingga isoelektris di V3. Pada keadaan HVK (B), ruang jantung bertambah besar dan mengalami perubahan menjadi lebih ke arah kiri, inferior dan posterior dan vektor jantung mengalami perubahan lebih posterior (panah hitam). Sadapan prekordial V3 dan V4 akan terekam dengan aksis yang lebih negatif dengan peningkatan amplitudo di gelombang $\mathrm{S}$ (gelombang $\mathrm{S}$ di V4 lebih dalam). Pada sadapan V4 arah vector menjauhi sadapan V4 menyebabkan gelombang $\mathrm{R}$ yang dangkal dan gelombang $S$ yang dalam. ${ }^{6}$

Hasil dari studi Peguero mendapati bahwa kriteria PLP merupakan kriteria terbaik dalam menilai HVK dari EKG dengan sensitivitas $57 \%$ dan spesifisitas $90 \%$, sedangkan kriteria Cornell memiliki sensitivitas $35 \%$ dan spesifisitas $92 \%$, serta kriteria Sokolow-Lyon memiliki kemampuan terendah dengan sensitivitas $17 \%$ dan spesifisitas $98 \% .^{6}$

\section{KESIMPULAN DAN SARAN}

\subsection{Kesimpulan}

- Hipertrofi ventrikel kiri yaitu peningkatan massa ventrikel kiri yang bisa disebabkan peningkatan teba dinding atau ukuran kavitas atau keduanya

- Hipertrofi ventrikel kiri telah ditunjukkan menjadi faktor risiko untuk komplikasi kardiovaskular di massa depan dan kematian.

- HVK menyebabkan 5 perubahan utama EKG : peningkatan voltase QRS, peningkatan durasi QRS, Deviasi aksis ke kiri, perubahan repolarisasi ST-T dan abnormalitas gel P.

- Terdapat 36 kriteria EKG yang telah disahkan oleh AHA untuk diagnosis HVK, umumnya berdasarkan voltase listrik jantung namun ada juga kriteria yang menggunakan beberapa parameter seperti skor romhilt estes namun sensitivitasnya masih rendah.

- Kriteria baru EKG HVK diharapkan mempunyai nilai tambahan diagnostik untuk mendeteksi adanya HVK khususnya pada fasilitas kesehatan dimana ekokardiografi belum tersedia.

\subsection{Saran}

Perlu dilakukan penelitian lebih lanjut untuk menilai peranan EKG dalam memprediksi hipertrofi ventrikel kiri dan geometri ventrikel kiri abnormal pada pasien hipertensi.

\section{DAFTAR PUSTAKA}

1. Cuspidi C, Sala C and Grassi G. Detection of left ventricular hypertrophy in obesity : mission impossible? Jhypertension. 2013;31:1-3.

2. Oseni A, Qureshi W and Almahmoud M. Left ventricular hypertrophy by ECG versus cardiac MRI as a predictor for heart failure. Heart. 2017;103:49-54.

3. Alfakih K, Walters $\mathrm{K}$ and Hypertension TJ. New gender-specific partition values for ECG criteria of left ventricular hypertrophy: recalibration against cardiac MRI. Hypertension. 2004;44:175-17.

4. Hancock E, Deal B and Mirvis D. AHA/ACCF/HRS recommendations for the standardization and interpretation of the electrocardiogram: part $\mathrm{V}$ : electrocardiogram changes associated with cardiac chamber hypertrophy: a scientific statement from the American Heart Association Electrocardiography and Arrhythmias Committee, Council on Clinical Cardiology; the American College of Cardiology Foundation; and the Heart Rhythm Society. J Am Coll Cardiol. 2009;53:992-1002.

5. Mancia G, Fagard R and Narkiewicz K. $\mathrm{ESH} / \mathrm{ESC}$ Guidelines for the management of arterial hypertension: the Task Force for the management of arterial hypertension of the 
European Society of Hypertension (ESH) and of the European Society of Cardiology (ESC). J Hypertens. 2013;31:1281-57.

6. Peguero J, LoPresti $\mathrm{S}$ and Perez J. Electrocardiographic Criteria for the Diagnosis of Left Ventricular Hypertrophy. J Am Coll cardiol. 2017;69:1694-703.

7. Shenasa M and Shenasa H. Hypertension, left ventricular hypertrophy, and sudden cardiac death. Int Journ of Cardiol. 2017;237:60-63.

8. Lang $\mathrm{R}$, Bierig $\mathrm{M}$, Devereux $\mathrm{R}$ and Flaschskampf F. Recommendations for chamber quantification : A report from the American Society of Echocariography's guidelines and standards committee and the chamber quantification writing group, developed in conjunction with the European Association of echocardiography, a branch of the European Society of cardiology. Journal of American Society of Echo. 2005;18:1440-63.

9. Baltazar R. Chamber enlargment and hypertrophy Basic and bedside electrocardiography Philadelphia; 2009: 6873.17 .

10. Goldberger A, Goldberger $\mathrm{Z}$ and Shvilkin A. Goldberger's Clinical Electrocardiography: A Simplified Approach Elsevier/Saunders. 9 ed.; 2017.

11. Mehta A, Jain A, Mehta M and Billie M. Usefulness of left atrial abnormality for predicting left ventricular hypertrophy in the presence of left bundle branch block. Am J Cardiol. 2000;85:534.

12. Okin P, Devereux R and Nieminen $M$. Relationship of the electrocardiographic strain pattern to left ventricular structure and function in hypertensive patients: the LIFE study. Losartan Intervention For End point. J Am Coll Cardiol. 2001;38:514.

13. Ganau A, Devereux R and Roman J. Patterns of left ventricular hypertrophy and geometric remodeling in essential hypertension. $j \mathrm{Am}$ Coll Cardiol. 2016;92:9061-7.
14. Surawicz B and Knilans TK. ventricular enlargement chou's electrocardiography in clinical practice. sixth edition ed: Saunders; 2008(6th edition).

15. Mirvis D and Goldberger A. Electrocardiography. In: D. Zipes, P. Libby and R. Bonow, eds. Braunwald's Heart Disease: A Textbook of Cardiovascular Medicine. 11 ed. philadelphia: Elsevier/Saunders Company; 2018.

16. Bacharova L. Electrocardiography-left ventricular mass discrepancies in left ventricular hypertrophy: electrocardiography imperfection or beyond perfection? 42. 2009:593-6.

17. Crow R, Prineas R, Rautaharju P, Hannan P and Cardiology PTAJo. Relation between electrocardiography and echocardiography for left ventricular mass in mild systemic hypertension (results from treatment of mild hypertension study). Am J Cardiol. 1995;75:1233-1238. 